\title{
Diabetes mortality and causes of death in Benghazi: a 5 -year retrospective analysis of death certificates
}

\author{
R.B. Roaeid ${ }^{7}$ and A.A. Kablan ${ }^{1}$
}

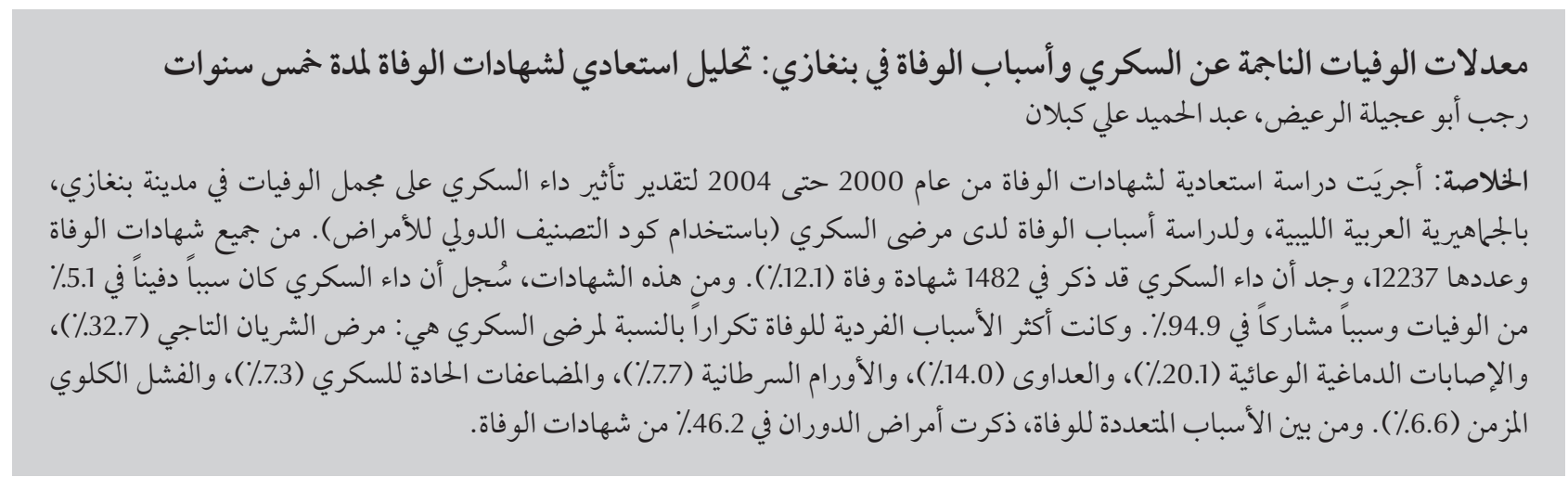

ABSTRACT A retrospective study of death certificates from 2000 to 2004 was made to estimate the contribution of diabetes to total mortality in Benghazi, Libyan Arab Jamahiriya, and to study the causes of death among diabetics (coded using the International Classification of Diseases). Of 12237 death certificates, 1482 (12.1\%) mentioned diabetes. Of these, diabetes was recorded as the underlying cause in $5.1 \%$ of deaths and a contributory cause in $94.9 \%$. The most frequent single causes of death for diabetics were: coronary artery disease $(32.7 \%)$, cerebrovascular accident (20.1\%), infections (14.0\%), malignancies (7.7\%), acute complications of diabetes (7.3\%) and chronic renal failure (6.6\%). Among multiple causes of death, circulatory diseases were mentioned on $46.2 \%$ of death certificates.

Mortalité due au diabète et causes des décès à Benghazi : une analyse rétrospective des certificats de décès sur cinq ans

RÉSUMÉ Une étude rétrospective des certificats de décès délivrés entre 2000 et 2004 a été réalisée afin d'estimer la part du diabète dans la mortalité totale à Benghazi (Jamahiriya arabe libyenne) et d'examiner les causes de décès chez les sujets diabétiques (sur la base des codes de la Classification internationale des maladies). Sur 12237 certificats de décès, 1482 (12,1\%) mentionnaient le diabète. Parmi ceux-ci, le diabète figurait comme cause initiale dans 5,1 \% des décès et comme cause ayant contribué au décès dans 94,9\% d'entre eux. Les causes de décès uniques les plus fréquentes chez les diabétiques étaient : les coronaropathies (32,7 \%), les accidents vasculaires cérébraux (20,1\%), les infections (14,0\%), les cancers (7,7 \%), les complications aiguës du diabète $(7,3 \%)$ et l'insuffisance rénale chronique (6,6\%). Parmi les causes de décès multiples, les maladies circulatoires figuraient sur 46,2\% des certificats de décès. 


\section{Introduction}

Despite improvements in the prognosis of individuals with diabetes, mortality is still 2 to 4 times higher for this group compared with the general population, with life expectancy reduced by up to one-third [1]. They have a significantly higher mortality than controls both from all causes and from circulatory diseases [2]. The excess global mortality attributable to diabetes in the year 2000 was estimated to be 2.9 million, equivalent to $5.2 \%$ of all deaths [3]. Yet mortality attributable to diabetes is underestimated due to under-reporting of diabetes on death certificates [4]. Although figures obtained from death certificates have limited use in research or health planning [5], they do provide comprehensive data, making them useful for studying long-term trends [6].

Benghazi is the second largest city in the Libyan Arab Jamahiriya, situated along the Mediterranean seaboard, with a population that increased from 575900 in 1991 to 803300 in 2000 [National Census and Statistics Department, personal communication]. The prevalence of diabetes in a community study in Benghazi in 2001 was found to be $14.1 \%$ [7]. A 5-year study of diabetes mortality was carried out in Benghazi in 1986-90 [8], but since then no further studies have been undertaken. The aim of this study was to update the data on diabetes mortality and causes of death in Benghazi.

\section{Methods}

Benghazi municipality covers all 51 districts (communes) of the city. All home deaths and all deaths in Benghazi hospitals are registered in the Benghazi central office for deaths. Non-Libyans have a separate register.

All death certificates of Libyan citizens registered during the 5-year period 1 January 2000 to 31 December 2004 were examined and data on age, sex and cause(s) of death were collected from certificates that mentioned diabetes. For analysis, the causes of death recorded on the death certificate were coded to the nearest code of the International Classification of Diseases, 10th revision (ICD-10) [9]. Diabetes as an underlying cause of death was defined if death was due to diabetic ketoacidosis, hypoglycaemia, or hyperosmolar nonketotic hyperglycaemia. Total mortality during the study period was obtained from the register of deaths.

\section{Results}

During the study period there were 12237 deaths recorded in Benghazi: 7071 males and 5166 females. A total of 1482 (12.1\%) death certificates mentioned diabetes: 758 (51.1\%) females and 724 (48.9\%) males. The mean age at death of this group was 63.8 years (65.4 years for males and 62.3 years for females), and $82(5.5 \%)$ were $<45$ years old at death.

Of all death certificates mentioning diabetes, 1038 (70.0\%) recorded a single cause of death, 153 (10.3\%) 2 causes and 291 (19.7\%) 3 or more causes. Diabetes (ICD-10: E10-E14) as the underlying cause of death was recorded in 76 certificates (5.1\%) and as a contributory cause of death in 1406 (94.9\%).

Coronary artery disease was recorded on $32.7 \%$ of 1038 death certificates with a single cause of death (Table 1): $25.1 \%$ due to acute myocardial infarction and $7.5 \%$ due to ischaemic heart disease. Cerebrovascular diseases were the next most common cause of death (20.1\%). Therefore circulatory diseases (ICD-10: I00-199) were the most frequently reported single cause of death in people with diabetes (52.8\%).

Infections (excluding tuberculosis) (14.0\%) were the next most common single cause of death (Table 1). Acute metabolic complications of diabetes (diabetic ketoacidosis, hypoglycaemia and hyperosmolar nonketotic hyperglycaemia) accounted for $7.3 \%$ of total deaths due to a single cause. Chronic renal failure was mentioned on $6.6 \%$ of death certificates with a single cause of death, malignancies on $7.7 \%$ and tuberculosis on $0.5 \%$.

Circulatory diseases were also included as the cause of death on 136 death certificates for the 444 cases with 2 or more causes. Aggregating the multiple causes of death, circulatory diseases were mentioned on 684/1482 (46.2\%) of death certificates.

Among the 82 diabetics aged $<45$ years at death, acute diabetic complications accounted for $35.1 \%$ of deaths, chronic renal failure for $18.9 \%$, coronary artery disease for $8.1 \%$ and infections for $13.5 \%$.

\section{Discussion}

Diabetes accounted for $12.1 \%$ of total deaths in Benghazi from 2000 to 20004, which is almost double the figure of $6.4 \%$ recorded in the previous study in Benghazi 14 years earlier (1986-90) [8]. This increase might be explained by the high prevalence of diabetes in the Libyan Arab Jamahiriya (14.1\%) [7] or because certifying physicians have become more aware of the importance of reporting diabetes on death certificates. However, in view of the fact that diabetes is known to be underreported on death certificates $[10,11]$, the magnitude of the problem might be even greater than this. Certainly, our figure is considerably lower than that of $38 \%$ reported from France [12] and $24 \%$ from Western Australia [13]. It is comparable to $9.3 \%$ from Singapore [10] but higher than figures from other developing countries: $2.7 \%$ from north India [14], 2.8\% from Kashmir [15] and $6.5 \%$ from Jamaica [16]. 


\begin{tabular}{|c|c|c|c|c|}
\hline \multirow[t]{2}{*}{ Cause of death (ICD-10 code) } & \multirow{2}{*}{$\begin{array}{c}\text { Males } \\
\text { No. }\end{array}$} & \multirow{2}{*}{$\begin{array}{c}\text { Females } \\
\text { No. }\end{array}$} & \multicolumn{2}{|c|}{ Total } \\
\hline & & & No. & $\%$ \\
\hline Coronary artery disease & 175 & 164 & 339 & 32.7 \\
\hline Acute myocardial infarction (I21) & 137 & 124 & 261 & - \\
\hline Ischaemic heart disease (I25) & 38 & 40 & 78 & - \\
\hline Cerebrovascular diseases (I60-I69) & 106 & 103 & 209 & 20.1 \\
\hline Infection & 70 & 75 & 145 & 14.0 \\
\hline Septicaemia (A02.1) & 34 & 42 & 76 & - \\
\hline Pneumonia (J15) & 30 & 26 & 56 & - \\
\hline Meningitis (G00) & 8 & 5 & 13 & - \\
\hline Malignancy & 46 & 34 & 80 & 7.7 \\
\hline Lung (C34) & 23 & 0 & 23 & - \\
\hline Gastrointestinal tract $(\mathrm{C16}, \mathrm{C18})$ & 10 & 18 & 28 & - \\
\hline Prostate (C61) & 5 & 0 & 5 & - \\
\hline Other & 8 & 16 & 24 & - \\
\hline Diabetes mellitus & 46 & 30 & 76 & 7.3 \\
\hline Diabetic ketoacidosis (E10) & 25 & 14 & 39 & - \\
\hline Hypoglycaemia (E16.0) & 20 & 13 & 33 & - \\
\hline Hyperosmolar nonketotic hyperglycaemia (E11) & 1 & 3 & 4 & - \\
\hline Chronic renal failure (N18) & 38 & 31 & 69 & 6.6 \\
\hline Chronic obstructive pulmonary disease (J40-J46) & 25 & 15 & 40 & 3.9 \\
\hline Liver cirrhosis (K72.1) & 18 & 20 & 38 & 3.7 \\
\hline Acute renal failure (N17) & 5 & 9 & 15 & 1.4 \\
\hline Gastrointestinal haemorrhage (K92) & 6 & 5 & 11 & 1.1 \\
\hline Other endocrine disease (EO3.5, EO5.5, E23, E27.2) & 2 & 9 & 11 & 1.1 \\
\hline Tuberculosis (A15) & 3 & 2 & 5 & 0.5 \\
\hline Total & 540 & 497 & 1038 & 100.0 \\
\hline
\end{tabular}

The mean age at death of people with diabetes (63.8 years) was lower than in New Zealand (78 years) [17]. In our study, a single cause of death was mentioned on $70.0 \%$ of death certificates, 2 causes on $10.3 \%$, and 3 or more causes on $19.3 \%$, compared with $60.2 \%$, $26.4 \%$ and $6.0 \%$ respectively from Kash$\operatorname{mir}[15]$.

Considering the cases of multiple causes of death, circulatory diseaseswere recorded in $46.2 \%$ of death certificates of diabetics, which is comparable to $50 \%$ reported from the 1986-90 Benghazi study [8], 48.0\% from north India [14], 50\% from Otago [17],35.0\% from Japan [18], 49.1\% and 46\% from the United Kingdom (UK) [19,20]. Higher rates have been reported in Western Australia (63\%) [13] and in another UK study (71\%) [21], while lower rates were found in Kashmir (30.1\%) [15] and among Oklahoma Indians (38\%) [22]. Libyans now have a more sedentary lifestyle, with consumption of high fat, high carbohydrate foods and lack of exercise, mimicking the lifestyles of more developed countries.

Among the 1038 death certificates with a single cause of death, coronary artery disease was the most frequently mentioned cause of death in diabetics (32.7\%), compared with $34 \%$ in a hospital-based study in Benghazi [23] and 36\% in the United States of America (USA) [24], but higher than the
13.8\% for aboriginal Australians [25], $17.4 \%$ from north India [14], 16.4\% from Kashmir [15] and 20.5\% from Japan [18]. Among those with vascular diseases, 261 (38.2\%) deaths were due to myocardial infarction compared with $28 \%$ from Benghazi in the 1986-90 study of death certificates [8], and 19\% from a 1-year hospital study in Benghazi in 2002 [23]. Diabetes is known to accelerate the onset of cardiovascular disease. Changes in diet and physical activity in the Libyan Arab Jamahiriya (the traditional Libyan nomadic life no longer exists) may contribute to an increased incidence of cardiovascular disease. Increased life expectancies and improved health care facilities for acute 
diabetic complications may add to increasing life expectancy among diabetics and hence a greater risk of dying from cardiovascular disease.

Acute cerebrovascular accident was the second leading single cause of death in $20.1 \%$ of cases, compared with $22 \%$ from the hospital studyin Benghazi [23] and $38.6 \%$ from the $1986-90$ record study from Benghazi [8]. This is higher than the $14.5 \%$ from Japan [18], 13.8\% from Kashmir [15] and 6\% in Mexican, Puerto Rican and Cuban Americans [26], 10.5\% from Taiwan [27] and 6\% in the USA [24], but lower than $30.6 \%$ from north India [14].

We found that infections, excluding tuberculosis, are still an important cause of death among diabetics (14.0\%), a figure that is comparable to earlier reports from Benghazi of $12.0 \%$ and $11 \%[8,23]$. However, much higherfigureshave been reported among aboriginal Australians (20.8\%) [25], in Kashmir (33.8\%) [15] and in north India (46.5\%) [14]. Tuberculosis was reported on $0.5 \%$ of death certificates compared with $1.7 \%[8]$, and $1 \%$ [23] from Benghazi.

Malignancies were recorded on 80 (7.7\%) death certificates with a single cause of death, similar to $8.4 \%$ from the Benghazi 1986-90 study [8], and $8 \%$ among Mexican, Puerto Rican and Cuban Americans [24], but lower than $18.5 \%$ from Taiwan [27], 12.0\% among Oklahoma Indians [22], and $21 \%$ in the TRIAD study [24]. This is probably related to a lack of proper diagostic facilities for malignancies so many cases might have been missed.
Chronic renal failure was reported on $6.6 \%$ death certificates of diabetics with a single cause of death, a decline from the figure of $14.5 \%$ in $1986-90$ in Benghazi [8]. This is probably due to the recently developed nephrology centres in Benghazi. Studies in other countries show $9.7 \%$ from north India [14], 22.3\% among aboriginal Australians [25] and 30.9\% from Kashmir [9].

Diabetes was recorded as the cause of death for $5.1 \%$ of deaths. This is comparable to the rate from death certificates in Benghazi 14 years earlier (6.4\%) [8], but lower than the hospital-based study in Benghazi (9\%) [23]. Other international figures are: $6.2 \%$ from north India [14], 10\% from USA [16], 16.7\% from Kashmir [15], 24\% from Western Australia [10], 28.8\% from Taiwan [25], and $44 \%$ in Cuban Americans [26]. Low diabetes-related mortality agrees with our previous report and may be related to earlier diagnosis and the availability of treatment facilities

Among those diabetics aged $<45$ years at death, acute diabetic complications accounted for $35.1 \%$ of deaths, compared with $32 \%$ from Sweden [28], 32\% from Norway [29], $9 \%$ from Ukraine [30] and 2\% from France [4]. Mortality due to chronic renal failure in this age group was $18.9 \%$ compared with $69 \%$ from Ukraine [30]. Infections were the cause of death in $13.5 \%$. Coronary artery disease was the cause of death in $8.1 \%$ compared to $9 \%$ from Ukraine [30]. The high mortality among those aged $<45$ years due to metabolic complications of diabetes and chronic renal failure reflects poor control. This is not due to lack of treatment, which is free of charge in our country, but probably due to lack of health education and of certain specific diagnostic tools that help in detecting those who are at risk and educating them properly. These facilities are now becoming available.

The study had some limitations. No distinction between type 1 and type 2 diabetes was recorded; however, since $3.7 \%$ of diabetics in Benghazi were assessed as having type 1 diabetes [31], we can assume that the majority of deaths in this study occurred in type 2 diabetics. Since underreporting of diabetes on death certificates is well known, ranging from $35 \%$ to $55 \%[10,11]$, we can assume that many cases were not reported. Finally many undiagnosed diabetics might have been missed.

\section{Conclusions}

Diabetes is a major health problem in Benghazi and an important cause of mortality. The mortality from diabetes appears to have nearly doubled over almost 15 years. Deaths from chronic renal failure have declined in this period. Circulatory diseases were still the main causes of death in diabetics, with acute myocardial infarction at the top of the list.

\section{Acknowledgements}

We give special thanks for Professor Samir Helmy Assaad Khalil, Professor of Medicine, Alexandria University, Egypt, for his valuable comments.

\section{References}

1. Brown LJ, Scott RS, Moir LM. All-cause mortality in the Canterbury (New Zealand) insulin-treated diabetes registry population. Diabetes care, 2001, 24:56-63.

2. Gatling W et al. Mortality rates in diabetic patients from a community-based population compared to local age and sex matched controls. Diabetes medicine, 1997, 14:316-20.
3. Roglic $\mathrm{G}$ et al. The burden of mortality attributable to diabetes: realistic estimates for the year 2000. Diabetes care, 2005, 28(9):2130-5.

4. Penman A. Excess mortality due to diabetes in Mississippi and the estimated extent of underreporting on death certificates. Journal of the Mississippi State Medical Association, 2003, 44(10):319-25. 
5. Bhurgri A et al. Mortality statistics in South Karachi. Journal of the Pakistan Medical Association, 2001, 51(12):446-9.

6. Adelstein AM. Death certification and epidemiological research. British Medical Association, 1978, 2:1929-30.

7. Kadiki OA, Roaeid RB. Prevalence of diabetes mellitus and impaired glucose tolerance in Benghazi Libya. Diabetes \& metabolism, 2001: 27:647-54.

8. Roaeid RB, Kadiki OA. Mortality of diabetes mellitus from death certificates in Benghazi-Libya. Egyptian journal of diabetes, 1996, 1:47-8.

9. Manual of the international statistical classification of diseases, injuries and causes of death, 10th revision. Geneva, World Health Organization, 1992.

10. Cutter JL. Diabetes mortality in Singapore, 1991: a preliminary study. Singapore medical journal, 1998, 39:311-8.

11. Chen F et al. Death certification and New Zealand health information service (NZHIS) statistics for diabetes mellitus: an under-recognized health problem. Diabetes research and clinical practice, 2004, 63:113-8.

12. Jougla $\mathrm{E}$ et al. Analysis of diabetes-related mortality in France. Diabetes \& metabolism, 1991, 17:337-45.

13. Whittall DE et al. Deaths from diabetes are under-reported in national mortality statistics. Medical journal of Australia, 1990, 152:598-600.

14. Bhansali A, Chattopadhyay A, Dash RJ. Mortality in diabetes: a retrospective analysis from a tertiary care hospital in North India. Diabetes research and clinical practice, 2003, 60:119-24.

15. Zargar AH et al. Mortality in diabetes mellitus-data from a developing region of the world. Diabetes research and clinical practice, 1999, 43:67-74.

16. Alleyne SI et al. Mortality from diabetes mellitus in Jamaica. Bulletin of the Pan American Health Organization, 1989, 23:30614.

17. Coppell K, McBride K, Williams S. Under-reporting of diabetes on death certificates among a population with diabetes in Otago Province, New Zealand. New Zealand medical journal, 2004, 17:1207-17.

18. Sasaki A et al. A 15-year follow-up study of patients with noninsulin dependent diabetes mellitus (NIDDM) in Osaka, Japan.
Long-term prognosis and causes of death. Diabetes research and clinical practice, 1996, 34(1):47-55.

19. Morgan CL, Currie CJ, Peters JR. Relationship between diabetes and mortality: a population study using record linkage. Diabetes care, 2000, 23:1103-7.

20. Thomason MJ et al. Reporting of diabetes on death certificates using data from the UK Prospective Diabetes Study. Diabetes medicine, 2005, 22(8):1031-6.

21. Goldacre MJ et al. Trends in mortality rates for death-certificate-coded diabetes mellitus in an English population 197999. Diabetes medicine, 2004, 21:936-9.

22. Lee ET et al. A follow-up study of diabetic Oklahoma Indians. Mortality and causes of death. Diabetes care, 1993, 16:300-5.

23. Roaeid RB. Hospital admissions of diabetic patients in Benghazi. Diabetes international, 2002, 12:24-5

24. McEwen LN et al. Diabetes reporting as a cause of death: results from the Translating Research Into Action for Diabetes (TRIAD) study. Diabetes care, 2006, 29:247-53.

25. Phillips CB, Patel MS, Weeramathri TS. High mortality from renal diseases and infections in Aboriginal Australians with diabetes. Australian journal of public health, 1995, 19:282-6.

26. Smith CA, Barnett E. Diabetes-related mortality among Mexican Americans, Puerto Ricans, and Cuban Americans in the United States. Revista panamericana de salud pública, 2005, 18(6):381-7.

27. Tseng $\mathrm{CH}$. Mortality and causes of death in a national sample of diabetic patients in Taiwan. Diabetes care, 2004, 27(7):1605-9.

28. Waernbaum I et al. Excess mortality in incident cases of diabetes mellitus aged 15 to 34 years at diagnosis: a population-based study (DISS) in Sweden. Diabetologia, 2006, 49(4):653-9.

29. Skrivarhaug $\mathrm{T}$ et al. Long-term mortality in a nationwide cohort of childhood onset type 1 diabetic patients in Norway. Diabetologia, 2006, 49(2):298-305.

30. Telishevka M, Chenett L, McKee M. Towards an understanding of the high death rate among young people with diabetes in Ukraine. Diabetes medicine, 2001, 18:3-9.

31. Kadiki OA, Roaed RB. Epidemiological and clinical patterns of diabetes mellitus in Benghazi, Libyan Arab Jamahiriya. Eastern Mediterranean health journal, 1999, 5:6-13.

\section{Note from the Editor}

We wish to draw the kind attention of our potential authors to the importance of applying the editorial requirements of EMHJ when preparing their manuscripts for submission for publication. These provisions can be seen in the Guidelines for Authors, which are available online at http:// www.emro.who.int/emhj.htm, and are published at the end of the first issue of each volume. We regret that we are unable to consider papers that do not conform to the Guidelines. 